Journal of Social Sciences 5 (4): 411-415, 2009

ISSN 1549-3652

(C) 2009 Science Publications

\title{
Appropriate Model for Zoning Local Fish Conservation in front of Buddhist Temple on the Bank of the Chi River by Sustainable Community Participation
}

\author{
Somchob Poo-Inna, Song-Koon Jantakajon and Terdthai Pantachai \\ The Research Institute of North Eastern Arts and Culture, \\ Mahasarakham University, Mahasarakham, 44000 Thailand
}

\begin{abstract}
Problem statement: The fresh water fish in The Chi River was a major source of food of people living in this area. The objectives of this research were: (1) to study the historical background, current situation and problems of local fish conservation in front of The Chi River by community participation and (2) to find the appropriate model for zoning the local fish conservation on the bank of The Chi River by sustainable community participation. Approach: The research area in Esan Region for 6 provinces including: Chaiyapum, Mahasarakam, Kalasin, Roi-ed, Yasoton and Ubon-rachatani. The samples as informants were selected by Purposive Sampling including 27 experts, 81 practitioners and 27 general citizens. The instruments for collecting data consisted of The Structured Interview and Non-structured interview, participatory observation and non-participatory observation, focus group discussion and conference. Data were classified into groups based on the studied issues. They were investigated by Triangulation Technique and analyzed based on the specified objectives. The findings were presented by Descriptive Analysis. Results: For the research findings found that the fish species conservation in Chi River caused by the initiation of bureaucratic divisions based on the needs for increasing the number of fish in natural water origin where it began to decrease as well as the need of community by seeing the pattern in conservation of fish species from other areas leading by the abbot and community leaders. The public work sectors and politicians provided facilitation and support. Now, the water origin as the zone of local fish conservation called "Shelter Area" was clearly allocated. The social measure or community regulation was determined in order to be followed. The religious beliefs, tradition, or ritual were administered. There was thoroughly information service. The organization from community village was established. Participatory management was performed. For the appropriate model fro zoning, there were 3 parts: (1) The internal factor caused zoning local fish conservation in front of Buddhist Temple, (2) The external factor facilitated and supported the local fish conservation based on academic principles and (3) the implementation process with pattern, sequence and implementation based on the efficient administration and management system. Conclusion/Recommendations: The research fin dings of this study could be appropriately, efficiently and effectively sustainable used as a guideline for zoning local fish conservation in front of Buddhist Temple on the bank of Chi River as well as other rivers in the future.
\end{abstract}

Key words: Appropriate, conservation, Buddhist, temple, sustainable, community, participation, Chi River

\section{INTRODUCTION}

The nature and environment was depended with each other. As a result, there was a support or assistance for a long period of time. In recent time, the large amount of nature was destroyed by human beings. The forest was very few. The river and canal were rotten. The number of many kinds of aquatic animal was decreased and extinct. It was caused because human beings didn't take care of it. They demolished and did not use benefit from the nature with the awareness of its value. In Thailand, there were various ways of ecological system including the land ecological system with many kinds of forest and water ecological system with fresh water, brackish water and salt water. Thai people had to depend on both direct and indirect ecological system. Specifically, people in rural area who had to depend on the nature as their food origin and stream for agriculture as well as daily life whereas the urban people had to depend on the natural product

Corresponding Author: Somchob Poo-Inna, The Research Institute of North Eastern Arts and Culture, Mahasarakham University, Maha Sarakham, 44000 Thailand Tel: +66-43-721686134 
and agriculture from rural sector as well as water as raw material in producing water supply and recreation area. Now, the government planned the policy in solving problem of poverty by viewing the sufficient food origin, clean water for subsistence and consumption, living in residence based on personal condition, having life security and safety as well as accessing various kinds of public service. Therefore, the management of resource and ecological system for alleviating problem of poverty, was a major strategy by focusing on discovery of model in appropriately and sustainably using natural resource.

Chi River was a major river flowing through the central part of North East Region. It fed many people's lives in the agriculture and fishery, as a food source full of local fish from the former time. But, in recent time, there was a continuously decreasing number of fish until it was worrisome. So, it was indispensable for finding technique of how to conserve the local fish species to be sustainably existed and increased. Thai society in North East Region still focused on and had firm faith in religious institute. Consequently, it was the motivation of people to be obedient with and follow in order to participate in local fish conservation together with Chi River forever. Therefore, this research had to be conducted.

Purpose and objective: The objectives of this research were to study: (1) The historical background of local fish conservation in front of Chi River on the bank of Buddhist Temple by community participation, (2) The current situation and problems of local fish conservation and (3) The appropriate model of local fish conservation in front of Buddhist Temple on the bank of Chi River by sustainable community participation.

\section{MATERIALS AND METHODS}

This study was a qualitative study. The samples were selected by Purposive Sampling in the area of Chiayapum, Mahasarakham, Kalasin, Roi-ed, Yasoton and Ubon-rachatani provinces, by using the instruments using for collecting data were The Survey Form, Observation Form, Interview Form and Focus Group Discussion. For data collection, the researcher collected data from field study, concluded and discussed the findings by descriptive analysis.

\section{RESULTS}

The research findings found that the fish specie conservation caused by the initiation of bureaucratic divisions in order to increase the number of fish in natural water source since the fish were dead by water pollution and eaten by humans. The fish were officially freed and given fish food at the beginning period. The fish raising was provided. The prohibition in catching aquatic animal in the local fish conservation area was released. Later on, the abbot, community leader and villagers were empowered for further management. It was related to the project of fish conservation in front of Buddhist Temple honored for The His Majesty The King as celebration his royal crown property for 50 years, the research project of Buddhist Way of specie conservation of fish in front of Buddhist Temple, the project of beautiful-clear water canal and the project of conservation of fish in front of Buddhist Temple. The Department of Fishery collaborated to be loyal to and love His Majesty The King. Besides, it caused by the community needs by viewing model of local fish conservation from other areas. Then, it was implemented in their own community by focusing on community participation including the offices in locality, politicians, or private sectors seeing an importance in facilitating, supporting and enhancing by managing the tour places.

According to current situation of problems for local fish conservation, found that: (1) there was a shortage of fish food in every where, (2) the secret fish catching still be existed, (3) there were no rafts in 4 places, it was not convenient to feed the fish and see them closely, (4) the fish always died during April-May in Summer with scarce water. Consequently, the oxygen in water wasn't sufficient for breathing of fish, (5) there was flooding at the bank for a long time, the conserved fish fled by flowing water and (6) the competition of long boat in the water area of fish specie conservation, the fish were panic.

For community participation, found that every where allowed the community as follows: (1) collaborate in planning for implementation, (2) collaborate in practicing based on the specified plan of implementation, (3) collaborate in obtaining benefit and (4) collaborate in evaluation by the villagers and committee of local fish conservation regarding to worthwhile, the findings of performance of local fish conservation. Moreover, the committee of local fish conservation evaluated their own performance based on the assigned role and function in order to improve to be better.

According to the analysis of current situation of problems in local fish conservation in front of Buddhist Temple on the bank of The Chi River by community participation staring from 1993 until now (2008) in total area of 9 places, 6 places of case study were 
implemented, found that it caused by major factors as follows: (1) the abbot had strength, persistence, dedication and was respected by the villagers, (2) the community leader and villagers saw importance of the collaboration, persistence and dedication, (3) the support by politicians and related work offices, (4) the water origin with adequate ecological system such as Chi-long or Good and (5) the community participation, the villagers had feeling that they belonged to community.

Therefore, the model of conservation occurred from community needs as major source.

The appropriate model for zoning local fish conservation in front of Buddhist Temple on the bank of Chi River, found that: (1) the abbot and community leaders had to gain major characteristics as the leaders including dedication, intelligence, far sight vision, recent perception of news, appropriate conduct, being faithful and respected and justice and rationale of administration and management including; (1) planning as the preparation in different implementations to be ready for future implementation with efficiency, (2) the implementation of local fish conservation in front of Buddhist Temple on the bank of The Chi River according to steps, duration and specified budget based on the determined plans in order to have the highest level of efficiency, (3) the information service, there should be advertisement for people in the village, general people and related people to be informed thoroughly, the sign indicating local fish conservation "Shelter Area" that could be clearly seen, (4) the community participation, the community should be provided opportunity for collaborating in shared planning, practicing, obtaining benefit and evaluating the annual work practice performances periodically including before the implementation, during implementation and the end of implementation in the year round regarding to worthwhile of implementation, resource management with the highest level of efficiency and effectiveness. Later on, the information was corrected, improved and developed to be better, (2) the monks referred to the priest or Buddhist Novice staying at that temple were major power in second order or runner-up from the abbot. They provided fish food for selling and feeding fish in each day, took care of the temple area and the port of local fish conservation to be clean and beautiful. They also perform religious rites based on beliefs of local villagers, (3) the villagers were those who lived in community or village with local fish conservation. When they saw the importance, persisted, dedicated and participated in every step of implementation, it would very well alleviate the problems of various kinds of conflict.
The external factors of community consisted of: (1) the public officers including government officials or public officers encouraging, supporting and enhancing the implementation as well as providing knowledge of local fish conservation and other related areas including: (1) the officers of fishery from The Office of Fishery of the District or Province of those districts or provinces, (2) the officers from The Office of Subdistrict Administrative Organization or that Sub-district Municipality, (3) the pensioned government officials were the former government officials of fishery, developers, or teachers who were retired from their work, (2) the politicians both in local level and national level including the members of the Sub-district Administrative Organization, members of representative parliament and members of Senate, (3) the process of implementation in local fish conservation in front of Buddhist Temple, was the step of implementation through systematic process and collaboration from major persons like the abbot, community leaders, villagers, public officers and politicians who had to collaborate in implementing the activities of local fish conservation with pattern, sequence and following the management system with efficiency.

\section{DISCUSSION}

According to the research findings, could be explained as follows: For the historical background of the research area context, found that the lifestyle of Esan people who lived at Chi River, was related to agriculture and fishery for their living. For their well being, it included simple, tolerance and helpfulness. The social system included the relationship as relatives, respect in nature, focus on tradition. When the resources were decreased especially the fish species, conservation was started. It was supported by research findings of ${ }^{[2]}$ titled "Villagers' Participation in Beuk Fish Conservation". The villagers viewed that if this problem wasn't solved, this kind of fish would be extinct. The found issues were: (1) the villagers understood in fisher resource conservation and conservation for tourism and (3) the management of natural fishery resources had to be responsible by the public and villagers.

For current situation, the problem in local fish conservation in front of Buddhist Temple on the bank of Chi River by community participation, found that the area of case study of total of 9 places, 6 places had been implemented until now since the major factor as the abbot and community leaders who had strength, persistence, dedication and being faithful and respected 
by villagers. Moreover, the villagers saw the importance of collaboration, persistence and dedication, support from politicians and related work offices as water origin with appropriate ecological system of local fish conservation. It was supported by Leadership Theory of Solomon Ben ${ }^{[1]}$ stated that the leadership was characteristic of the persons who influenced the others, could be able to make the other persons to listen to them and agree with their group objective, follow the advice and information so that the group could be able to work according to the objective. For the role of leaders in rural society, it was always the service for other people with dedication for locality, desire to see growth and persist in doing goodness in every way in order to make changes, want to behave as a role model and initiate work as the example to be followed by the others most by hoping for development in community.

For the above major problem situations, found that in every place, there were secret fish catching in "Shelter Area." In some areas, there were no rafts for feeding fish and seeing fish closely. As a result, the inconvenience happened during April-May and the fish died since there was a little water but a too much fish. Oxygen in water wasn't sufficient for breathing. Furthermore, if there was flooding for months, the conserved fish fled away by water. The contest of long boat in the area of local fish conservation, the fish were panic and went to other places. It was supported by the findings of Pontawee Yodmongkon et al..$^{[4]}$ titled "Management of Natural Water Source connecting to Moon River, Goodkakeem Sub-district and Tabyai Subdistrict, Rattanaburi District, Surin Province, found various ways of ecological system. There was a large number of land animals and aquatic animals. But, there were changes in Goodkakeem because of many reasons: the increasing number of people and the development of the area of the bank in order to cut the stick for fishery, collapse of the bank, water wall for irrigation. The major problem was the construction of Raseesalai Dam that caused environmental changes of the dam. Consequently, there were some water weeds covering water source. Some kinds of fish and animals were extinct.

The appropriate model for zoning local fish conservation in front of Buddhist Temple on the bank of The Chi River by sustainable community participation, found that there had to include 3 aspects:

- The internal aspect consisted of people in community with sacrifice, wisdom, far vision, perception of news, good conduct, being faith and loyalty, justice, justice, rationale in administration and management with efficiency, broad information service and the priest gave an importance to conservation of fish at the port of temple

- The external factor consisted of the public officers and capitalists' support

- The process of implementation in local fish conservation in front of Buddhist Temple, consisted of steps through systematic process including the appointment of committee, determination of measure, community regulation, information service, creation of network with related work offices, follow up and evaluation and improvement for better work performance

It was supported by Structural Functionalism Theory of Wansiri's ${ }^{[3]}$ statement regarding to the study of people's behavior in society by citing viewpoint of Radlif Brown and Bronislow Malinowski' suggestion that the human beings had their basic needs which had to be served from society for 3 kinds:

- $\quad$ Physical and mental need

- The shared response of society members

- The symbol need

According to the above approaches and theories, could be explained the model for zoning local fish conservation in front of Buddhist Temple on the bank of Chi River. Moreover, those research studies could shed light on the model for zoning local fish conservation in front of Buddhist Temple $n$ the bank of Chi River, that there was an interaction with environmental ecological system of environment, local wisdom and limited resources. Consequently, the local fish conservation was successful with sustainable existence.

\section{CONCLUSION}

The findings from the study of appropriate model for zoning local fish conservation in front of Buddhist Temple on the bank of Chi River by sustainable community participation, it included the historical background, belief, tradition, ritual, local culture, current situation, problems of local fish conservation in front of Buddhist Temple on the bank of Chi River, were recognized. Moreover, The guidelines for determining the appropriate model for zoning local fish conservation in front of Buddhist Temple on the bank of Chi River by sustainable community participation. 


\section{REFERENCES}

1. Hiranto, U., 1981. Leading Art: The Art of Leaders. Odean Store Printing, Bangkok, ISBN: 974-276-420-4.

2. Wankanapon, A., 2001. Community Attitude toward Conservation of nearly extinct Buek Fish at Mae-ngad-somboonchon Dam, Mae-tang District, Chiengmai Province. An Independent Study Report for Master of Art, Chiengmai University, ISBN: 9745413461.
3. Wannasiri Ponwattana, 1997. Niyapan Anthropology, Society and Culture. Thammasat University, Bangkok, ISBN: 974533874.

4. Yodmongkon, Pontawee et al., 2004. Goodkakeem: Water Management of Thaiban Issue. The Office of Research Support Grant (ORG), The Region Office, Bangkok, ISBN: 974206374. 